\title{
Hydrogen Peroxide Detoxifying Enzymes Showed Different Activities at Different Timing in Host and Nonhost Plants In- teractions with Wheat Blast Fungus Magnaporthe Oryzae Triti- cum Pathotype
}

\author{
Dipali Rani Gupta ${ }^{1 *}$, Sanjida Khanom ${ }^{1 *}$, Ashwag Shami ${ }^{2 *}$, Md. Motiar Rohman ${ }^{3}$, Musrat Zahan Surovy ${ }^{1}$, Nur Ud- \\ din Mahmud1, Mirza Hasanuzzaman', and Kamel A. Abd-Elsalam ${ }^{5}$, Mahfuzur Rahman ${ }^{6}$ and Tofazzal Islam $^{1 *}$ \\ 1 Institute of Biotechnology and Genetic Engineering, Bangabandhu Sheikh Mujibur Rahman Agricultural \\ University, Gazipur-1706, Bangladesh; drgupta80@gmail.com (D.R.G.) \\ 2 Biology Department, College of Sciences, Princess Nourah bint Abdulrahman University, Riyadh, Saudi \\ Arabia; AYshami@pnu.edu.sa (A.S.) \\ 3 Genetics and Plant Breeding Division, Bangladesh Agriculture Research Institute (BARI), Joydebpur Gazi- \\ pur, Bangladesh; motiar 1@yahoo.com (M.M.R.) \\ 4 Department of Agronomy, Sher-e-Bangla Agricultural University, Dhaka, Bangladesh; mhzsauag@ya- \\ hoo.com (M.H.) \\ 5 Plant Pathology Research Institute, Agricultural Research Center (ARC), 12619, Giza, Egypt; kamelab- \\ delsalam@gmail.com (K.A.A.) \\ 6 Agriculture \& Natural Resources, Extension Service,West Virginia University, Morgantown, WV 26506, \\ USA; mm.rahman@mail.wvu.edu" mm.rahman@mail.wvu.edu (M.R.) \\ * Correspondence: tofazzalislam@yahoo.com (M.T.); Tel. +88-0171-4001414; AYShami@pnu.edu.sa (A.S.); Tel.: \\ +966-11-823-3175 (A.S.). \#Equally contributed
}

\begin{abstract}
Wheat blast caused by the hemibiotroph fungal pathogen Magnaporthe oryzae Triticum (MoT) pathotype, is a destructive disease of wheat in South America and Bangladesh. Generation of reactive oxygen species (ROS) is one of the defense responses in plants during the infection process by a pathogen. However, empirical evidence on regulation of ROS in wheat and other host and non-host plants towards MoT is limited. This study aimed to determine the susceptibility of some major cereals and weeds of Bangladesh and compare the antioxidant enzyme activities in host and non-host plants in response to artificial inoculation by MoT. Seedlings of wheat, maize, barley and swamp rice grass were susceptible to MoT and produced considerable number of conidia on infected leaves (host). Rice seedlings showed a resistant response in our laboratory conditions (nonhost). The activities of ROS-detoxifying enzymes; catalase (CAT), ascorbate peroxidase (APX), Glutathione peroxidase (GPX), Glutathione S-transferase (GST), Peroxidase (POX) increased in all plants after inoculation by MoT with a few exceptions. Interestingly, an early and very high accumulation of CAT was observed within 24 hours of inoculation (hai) in wheat, barley, maize and swamp rice grass while $\mathrm{H}_{2} \mathrm{O}_{2}$ concentration was low during that time and immediately after that (24-48 hai). In contrast, an early and high accumulation of $\mathrm{H}_{2} \mathrm{O}_{2}$ was observed in rice at 48 hai with little CAT activity only at a late stage. The APX, GST and POD activity was also increased due to the inoculation of MoT at the early stage of infection in rice but were very high at the disease progression stage in wheat, barley, maize and swamp rice grass. GPX activity gradually decreased with the increase of time in rice. Taken together, our results suggest that a robust and late induction of most of the antioxidant enzyme activities occurs in susceptible/host plants whereas an early induction of antioxidant enzyme activities occurs in resistant/ non-host plant but with slow kinetics.
\end{abstract}

Keywords: Antioxidant enzymes; hemibiotroph; reactive oxygen species; host-pathogen interaction; sporulation 


\section{Introduction}

Wheat blast disease caused by the filamentous fungus Magnaporthe oryzae Triticum (MoT) pathotype is a recurrent problem in wheat-growing regions. After its first emergence in Brazil, this disease spread to other neighboring countries of South America. Although the disease was mainly restricted in the tropical regions of South America [1], increasing trend of greenhouse gases and climatic change associated with global warming triggered its spread to other parts of the world. It spotted for the first time in Bangladesh in February 2016 devastating 1500 hectares of wheat crop with yield loss up to $100 \%$ [2]. Field pathogenomics revealed that the pathogen is a lineage of South American M. oryzae isolate and probably introduced in the country by seed trading $[2,3]$. A recent report showed that wheat blast pathogen MoT pathotype also caused disease on rain-fed grown wheat in Zambia where the disease incidence ranged from 50 to $100 \%$ [4].

M. oryzae is generally classified as a hemibiotrophic pathogen, which has a long biotrophic (asymptomatic) phase followed by a necrotrophic phase that leads to tissue collapse, necrosis and cell death $[5,6]$. The infection cycle of $M$. oryzae starts when three celled pyriform conidia germinate and produce appressorium after landing on the leaf surface and establish a biotrophic interaction with host plant [6]. Initial blast symptoms on leaves appear as diamond-shaped water-soaked lesions that gradually turn necrotic with the progression of time. Symptoms on wheat head become visible when M. oryzae colonize at the rachis and block nutrient translocation to the grains causing shriveled, small and underweight seeds $[7,8]$. Infected seeds are considered the primary source of long-range inoculum dispersal of M. oryzae from one place to another [9]. Besides seed, alternative hosts are also considered as a reservoir of overwintering inoculum of blast pathogen for disease outbreak [10]. A striking example is wheat blast outbreak in Brazil, which was the consequence of host jump of MoT isolates from perennial ryegrass due to loss of a host specificity determinant [11]. Wheat infecting $M$. oryzae isolate can infect some other Poaceae family plant species including barley, rye, oat and Setaria indica. Rice is considered a non-host for M. oryzae isolate of wheat and genetically distinct from each other [12, 13]. Host resistance of rice and wheat to $M$. oryzae is attributed to the gene for gene interactions [14] whereas non-host resistance of plants largely depends on a complex combination of constitutive and induced defense components [15]. For an efficient management strategy, it is important to determine the susceptibility of other plants especially close relatives of wheat to MoT isolates. These plants may serve as an overwintering reservoir of the pathogen and produce copious amount of conidia as alternative host plant [10]. We have previously shown that Bangladesh MoT isolates could develop symptoms on barley [2]. In this study, we tested the potential of some other cereals and grasses as alternative hosts for MoT.

Whether a plant would be susceptible or resistant to a pathogen depends on both pathogen and host/plant factors [16]. In response to a pathogen attack, plant triggers a series of defense reactions. Generation of reactive oxygen species (ROS) in plant cells by the attack of the pathogen is one of the earliest defense responses by the plant. The rapid accumulation of plant ROS at the pathogen attack site is a phenomenon known as oxidative burst, which causes direct toxicity to pathogens $[17,18]$. Among ROS, hydrogen peroxide $\left(\mathrm{H}_{2} \mathrm{O}_{2}\right)$ is one of the most stable and important players in determining plant cell redox state and signalling $[19,20]$. To remove the excess $\mathrm{H}_{2} \mathrm{O}_{2}$ generated during the hostpathogen interaction, several antioxidative enzymes are induced to scavenge $\mathrm{H}_{2} \mathrm{O}_{2}$ thereby keeping the concentration low in a plant cell for the continuity of cell function [19, 21]. Among the $\mathrm{H}_{2} \mathrm{O}_{2}$ scavenging enzymes, catalase (CAT) plays an important role in the rapid removal of this ROS with high capacity. Other antioxidative enzymes such as glutathione $S$-transferase (GST), ascorbate peroxidase (APX), glutathione reductase (GR), glutathione peroxidase (GPX) and peroxidase (POX) also contribute to $\mathrm{H}_{2} \mathrm{O}_{2}$ removal in the host defense mechanism against oxidative stress. However, the precise role POX, in the removal of $\mathrm{H}_{2} \mathrm{O}_{2}$ is still not clear but some studies showed that this enzyme generates $\mathrm{H}_{2} \mathrm{O}_{2}$ rather than removal [22]. 
$\mathrm{H}_{2} \mathrm{O}_{2}$ is produced differentially in plants during resistance responses to biotrophic pathogens and susceptible responses to necrotrophic and hemibiotrophic pathogens. It has been shown that $\mathrm{H}_{2} \mathrm{O}_{2}$ inhibits pathogen at biotrophic stage whereas large accumulation of $\mathrm{H}_{2} \mathrm{O}_{2}$ is required for subsequent cell death and pathogen reproduction [23]. Removal of $\mathrm{H}_{2} \mathrm{O}_{2}$ by catalase at both early and late stages makes wheat plants more susceptible, whereas $\mathrm{H}_{2} \mathrm{O}_{2}$ infiltration makes plants more resistant by the infection of hemibiotrophic pathogens such as Septoria tritici [24]. An increased concentration of $\mathrm{H}_{2} \mathrm{O}_{2}$ was observed in susceptible wheat varieties inoculated with $M$. oryzae at a later stage while the resistant variety maintained a constant level of $\mathrm{H}_{2} \mathrm{O}_{2}$ concentration [25]. Biochemical studies of wheat-M. oryzae pathosystem also showed that a more pronounced increase of POD, APX, GPX, GST, GR activity in resistant wheat variety compared to susceptible variety, which might play a key role to keep the $\mathrm{H}_{2} \mathrm{O}_{2}$ concentration lower [25]. Although a few studies documented enzymatic regulations of MoT infection and subsequent disease progression in the wheat plant, there is very little information available on similar processes that may take place during interactions of MoT with its alternative host or non-host in regards to their enzymatic regulations. Since $M$. oryzae can infect more than 50 plant species of Poaceae family, it is divided into several subspecies depending on their specific host. The research question is; how differently an alternative host or non-host plant defend itself when a different subspecies of M. oryzae attack it? Whether they employ their enzymatic regulation in a similar way to defend against MoT like a resistant one does or in a different way to cope with the pathogen? Therefore, it is important to know the enzymatic regulation of host, alternative host and non-host to MoT for a better understanding of the defense mechanism. In this study, we assessed the susceptibility of wheat, maize, barley, rice and swamp rice grass to MoT isolate and compared different antioxidant enzyme activity in the host and non-host plant during pathogen interaction to better understand the role of antioxidant enzymes in plant defense against M. oryzae.

\section{Materials and Methods}

\subsection{Plant Materials Collection and Growth Conditions}

The seeds of wheat, rice, barley and maize were collected from Plant Breeding Division, Bangladesh Agriculture Research Institute (BARI), Joydebpur, Gazipur. Seeds of swamp rice grass (Leersia hexandra), jungle rice (Echinochloa colonum), crowfoot grass (Dactyloctenium aegyptiacum), scrab grass (Digitaria sanguinalis), nutsedge (Cyperus rotundus) were collected from the agronomy field of Bangabandhu Sheikh Mujibur Rahman Agricultural University (BSMRAU) campus, Gazipur. Seeds were sown on a mixture of coarse sand and autoclaved soil in $20 \times 30 \mathrm{~cm}$ pots and kept in laboratory conditions for germination. In case of burmuda grass (Cynodon dactylon), young and fresh plantlets were collected from BSMRAU campus and 3-4 plantlets were planted in each of $20 \times 30 \mathrm{~cm}$ diameter pot. Seedlings were watered at regular intervals or as needed. The experiment was replicated three times.

\subsection{Conidia Production, Pathogenicity Assay in Plant and Determination of Inoculum Potential}

One virulent $M$. oryzae isolate of wheat BTJP4-5 was used for pathogenicity assay in this study. The isolate BTJP4-5 was collected from wheat blast infected field of the southwestern part of Bangladesh during the year 2016 and stored in dry filter paper at $-20{ }^{\circ} \mathrm{C}$. The filter paper pieces containing fungal conidia/mycelia were revived by spreading them on PDA medium followed by incubating at $25^{\circ} \mathrm{C}$ for 7 days. The inoculum was prepared following the method described by Gupta et al. [26] and pathogenicity assay was performed following the procedure described by Islam et al. [2]. Briefly, all seedlings at the 20-day-old growth stage were sprayed with sterilized water before $1 \mathrm{~h}$ of inoculation of conidia to maintain $80-90 \%$ humidity. M. oryzae conidial suspension was sprayed on all seedlings using a sprayer until run off. Immediately after inoculation, seedlings were covered with polythene for $24 \mathrm{~h}$ at room temperature $\left(22-30{ }^{\circ} \mathrm{C}\right)$ to maintain high humidity for fungal infection. After that polythene bags were removed, and plant were kept in natural conditions for symptom development. Plants were examined daily for lesion development. The disease severity index was calculated using an ordinal scale from 0 to 5 as 
previously described [27]. The disease severity index (DI) was scored as follows: lesion type $0=$ no visible reaction; $1=$ minute, pinhead-sized spots; $2=$ small brown to dark brown lesions with no distinguishable centers; $3=$ small eyespot shaped lesions with grey centers; $4=$ typical elliptical blast lesions with grey centers; $5=$ completely dead plant. Index values 0 and 1 were considered incompatible (no sporulation) and index values 2, 3,4 and 5 were considered compatible (sporulation). When different types of lesions were prevalent on a single leaf, the most abundant lesion type was considered for indexing. Inoculum potential of host plants was determined following the method described by Cruz et al. [28].

\subsection{Determination of Protein}

The protein concentration in leaf extracts was determined according to Bradford method [29] using BSA as a protein standard. For this method, $5 \mu \mathrm{L}$ extract of each sample was mixed with Bradford solution. Standard protein value was measured by a series of 5, 10, 15, 20, $25 \mu \mathrm{L}$ BSA with Bradford solution. All absorbance values were recorded spectrophotometrically.

\subsection{Measurement of $\mathrm{H}_{2} \mathrm{O}_{2}$}

$\mathrm{H}_{2} \mathrm{O}_{2}$ accumulation in leaves was measured according to the method described by $\mathrm{Yu}$ et al. [30]. The extract was prepared by homogenizing $0.5 \mathrm{~g}$ of leaf tissue with $3 \mathrm{~mL}$ of 50 $\mathrm{mM}$ K-phosphate buffer ( $\mathrm{pH}$ 6.5) at $4{ }^{\circ} \mathrm{C}$. The homogenate was centrifuged at $11,500 \times \mathrm{g}$ for $15 \mathrm{~min}$. The supernatant ( $3 \mathrm{~mL}$ ) was mixed with $1 \mathrm{~mL}$ of $0.1 \% \mathrm{TiCl}_{4}$ in $20 \% \mathrm{H}_{2} \mathrm{SO}_{4}(\mathrm{v} / \mathrm{v})$, and the mixture was then centrifuged at $11,500 \times \mathrm{g}$ for $15 \mathrm{~min}$ at room temperature. The absorption of the supernatant was measured at $410 \mathrm{nM}$ to determine the $\mathrm{H}_{2} \mathrm{O}_{2}$ content and expressed as micromole $\mathrm{g}^{-1} \mathrm{FW}$.

\subsection{Enzymes Extraction and Activity Assay}

For enzyme assay, leaf samples were collected at $0,24,48,72$ and $96 \mathrm{~h}$ after inoculation (hai) by MoT. To extract enzymes, $0.5 \mathrm{~g}$ of fresh leaf tissue was homogenized in $1 \mathrm{~mL}$ of $50 \mathrm{mM}$ ice-cold K-phosphate buffer (pH 7.0) containing $100 \mathrm{mM} \mathrm{KCl}, 1 \mathrm{mM}$ ascorbate, $5 \mathrm{mM} \beta$-mercaptoethanol, and $10 \%(\mathrm{w} / \mathrm{v})$ glycerol in a pre-cooled mortar. The homogenates were centrifuged at $11,500 \times \mathrm{g}$ for $12 \mathrm{~min}$, and the supernatants were used for determination of enzymes activity and protein content. All procedures were performed at $4{ }^{\circ} \mathrm{C}$. Enzyme activity from each sample was determined in 3 replications, and the each measurement was taken twice.

CAT (EC: 1.11.1.6) activity was measured according to the method described by Hossain et al. [31] by monitoring the decrease of absorbance at $240 \mathrm{~nm}$ for $1 \mathrm{~min}$ caused by the decomposition of $\mathrm{H}_{2} \mathrm{O}_{2}$. The reaction mixture contained $50 \mathrm{mM} \mathrm{K-P} \mathrm{buffer} \mathrm{(pH} \mathrm{7.0),}$ $15 \mathrm{mM} \mathrm{H}_{2} \mathrm{O}_{2}$, and enzyme solution in a final volume of $0.7 \mathrm{~mL}$. The reaction was initiated with enzyme extract, and the activity was calculated using the extinction coefficient of $39.4 \mathrm{M}^{-1} \mathrm{~cm}^{-1}$.

APX (EC: 1.11.1.11) activity was assayed following the method of Nakano and Asada [32]. The activity was measured by observing the decrease in absorbance at $290 \mathrm{~nm}$ as AsA was oxidized using an extinction coefficient of $2.8 \mathrm{mM}^{-1} \mathrm{~cm}^{-1}$.

GPX (EC: 1.11.1.9) activity was measured as described by Hasanuzzaman et al. [33] using $\mathrm{H}_{2} \mathrm{O}_{2}$ as a substrate. The oxidation of NADPH was recorded at $340 \mathrm{nM}$ for $1 \mathrm{~min}$, and the activity was calculated using the extinction coefficient of $6.62 \mathrm{mM}^{-1} \mathrm{~cm}^{-1}$.

GST (EC: 2.5.1.18) activity was determined spectrophotometrically by the method of Hossain et al. [31]. The increase in absorbance was measured at $340 \mathrm{nM}$ for $1 \mathrm{~min}$. The activity was calculated using the extinction coefficient of $9.6 \mathrm{mM}^{-1} \mathrm{~cm}^{-1}$.

POX (EC 1.11.1.7) activity was estimated according to Hemeda and Klein [34]. Activity was determined by the increase in absorbance at $470 \mathrm{nM}$ due to guaiacol oxidation for $1 \mathrm{~min}$ using extinction coefficient of $26.6 \mathrm{mM}^{-1} \mathrm{~cm}^{-1}$.

\subsection{Statistical Analysis}

The SPSS version 16 and Microsoft Office Excel 2010 program package were used for statistical analysis. The experimental design was completely randomized consisting of 
three replications for each treatment. Means comparison of the treatments was performed by LSD test $(\mathrm{P} \leq 0.05)$.

\section{Results}

\subsection{Susceptibility of Different Plant Species to MoT Isolate}

Wheat seedlings were highly susceptible to MoT isolates BTJP4-5. Diamond-shaped water-soaked lesions appeared on leaves of wheat seedlings at 72 hai by MoT. At the later stage, symptoms manifested as elliptical eye-shaped lesions with grey centres $(>4 \mathrm{~mm}$ diam), usually coalescing with each other and causing seedling death (Figure 1). Seedlings of barley were found highly susceptible (lesion type 4 and 5) when inoculated with MoT isolate BTJP4-5 Seedlings were completely dead at 15 days after inoculation. Unlike wheat and barley, rice seedlings did not show any lesion due to inoculation with MoT isolate (lesion type 0 ) indicating that MoT isolate not pathogenic on rice. However, seedlings of maize exhibited low to medium level of susceptibility (lesion type 2) to MoT isolate and only diamond-shaped water-soaked lesions were formed on the leaves but no collapsed or dead plants were observed even after one month of inoculation. We also tested the pathogenicity of MoT isolate on some grasses generally found in wheat and rice field. Among them, only swamp rice grass was susceptible (lesion type 4-5) to MoT isolate (Figure 1).

A

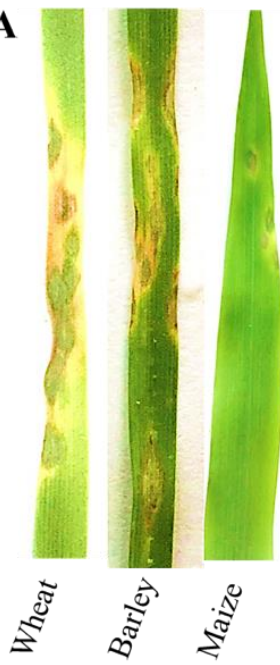

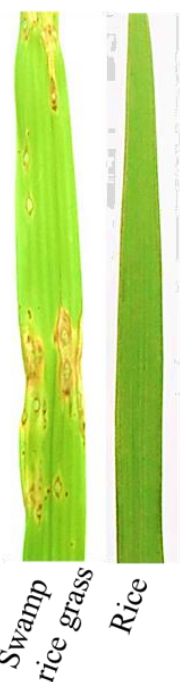
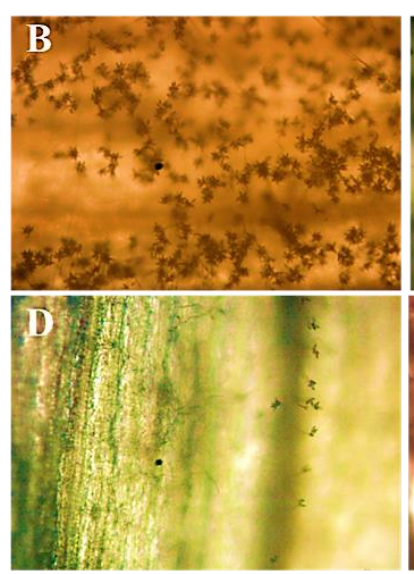

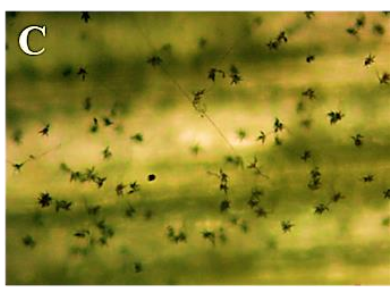

E

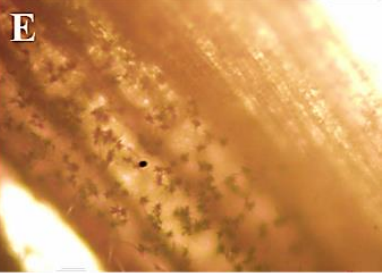

Figure 1. Development of disease symptoms (A) and sporulation potential of MoT isolate on leaves of wheat $(\mathbf{B})$, barley $(\mathbf{C})$, maize $(\mathbf{D})$ and swamp rice grass (E). Plants were inoculated with MoT isolate BTJP4-5 and development of disease symptoms were recoded 7-days after inoculation. Symptomatic leaves were cut and incubated for $24 \mathrm{~h}$ in a moist chamber to induce sporulation and photographs were taken under a microscope.

The sporulation potential of a pathogen is an important factor for a disease outbreak [28]. We estimated the sporulation potential of the MoT isolates on rice, wheat, barley, maize and swamp rice grass by counting the number of conidia under a microscope. MoT produced conidia on infected wheat, barley, maize and swamp rice grass (compatible interaction). The rate of conidia production was higher with infected wheat leaves in an average of 13,00,000-15,00,000 conidia per gram fresh leaf. Infected barley leaf produced 310000-370000 conidia per gram fresh leaf, whereas, infected swamp rice grass and maize leaf produced 280000-310000 and 1000-1400 conidia per gram fresh leaf, respectively (Figure 1B-E). No conidia were observed on rice leaves (incompatible interaction) (data are not shown).

\subsection{Activities of Antioxidant Enzymes}

The CAT activity was increased in all plants inoculated with MoT compared to their control (0 hai) but at different time points. In wheat, barley and swamp rice grass the 
highest CAT activity was observed at 24 hai of MoT inoculation the plant and it was 48, 47 and $50 \%$ higher than the control and decreased after that. Although rice and maize maintained a steady increase of CAT activity compared to their control increase of CAT activity $(108 \%)$ was higher in maize plant compared to rice $(6 \%)$ at 96 hai (Figure 2$)$.

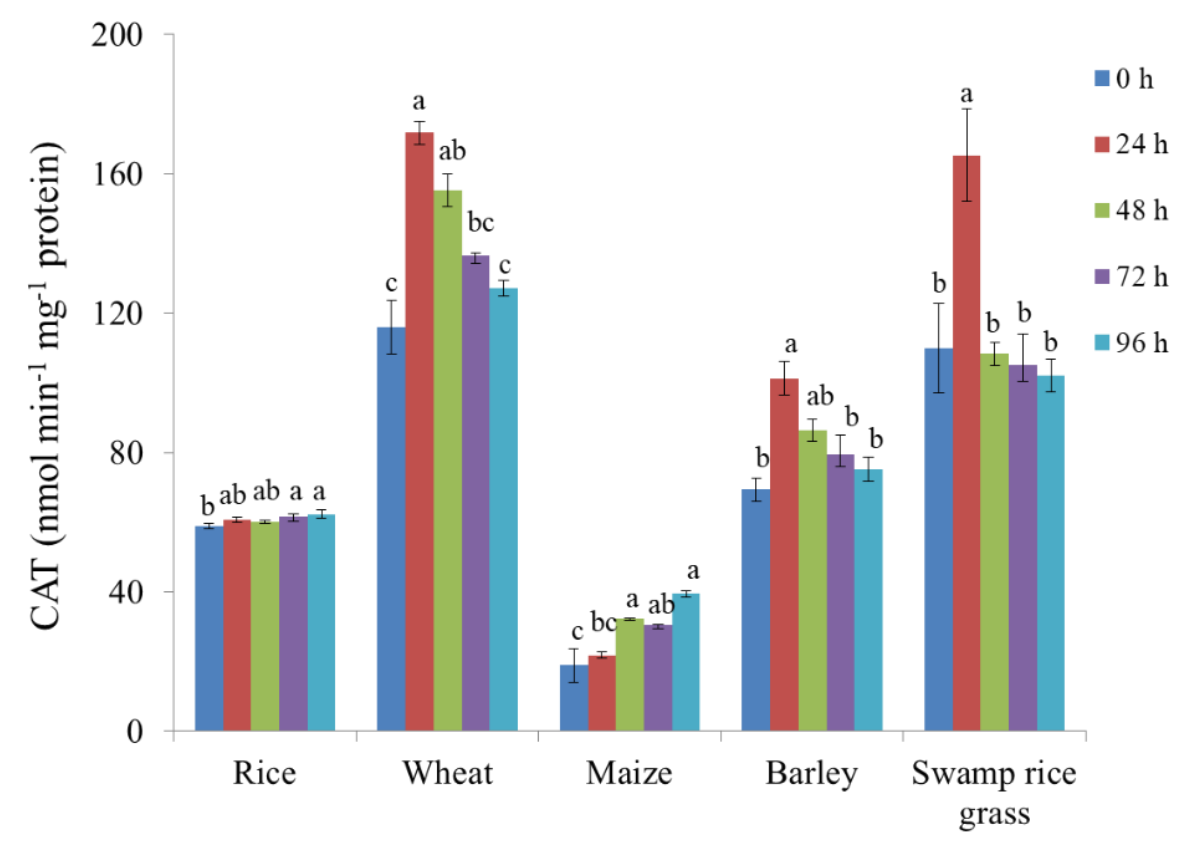

Figure 2. Activities of catalase (CAT) in leaves of rice, wheat, maize, barley and swamp rice grass plants inoculated with MoT isolate. Bars represent the mean values \pm standard error obtained for three independent experiments. Mean values in each treatment with the same letter(s) are not significantly different as assessed by Fisher's protected least significant difference (LSD) test at $\mathrm{p} \leq 0.05$.

The APX activity increased in all plants inoculated with MoT in all the sampling times compared to control. APX activity in rice plant was $43 \%$ higher over control at 24 hai and decreased after that. In wheat, maize and swamp rice grass, enhancement of APX activity started form 24 hai and reached a maximum at 96 hai, which was 50, 186, and $399 \%$, respectively, higher than control. Although the highest APX activity was observed in barley at 48 hai it stayed almost at the same level till 96 hai (Figure 3). Although the level decreased slightly after 48 hai, the difference was not statistically different (Figure $3)$.

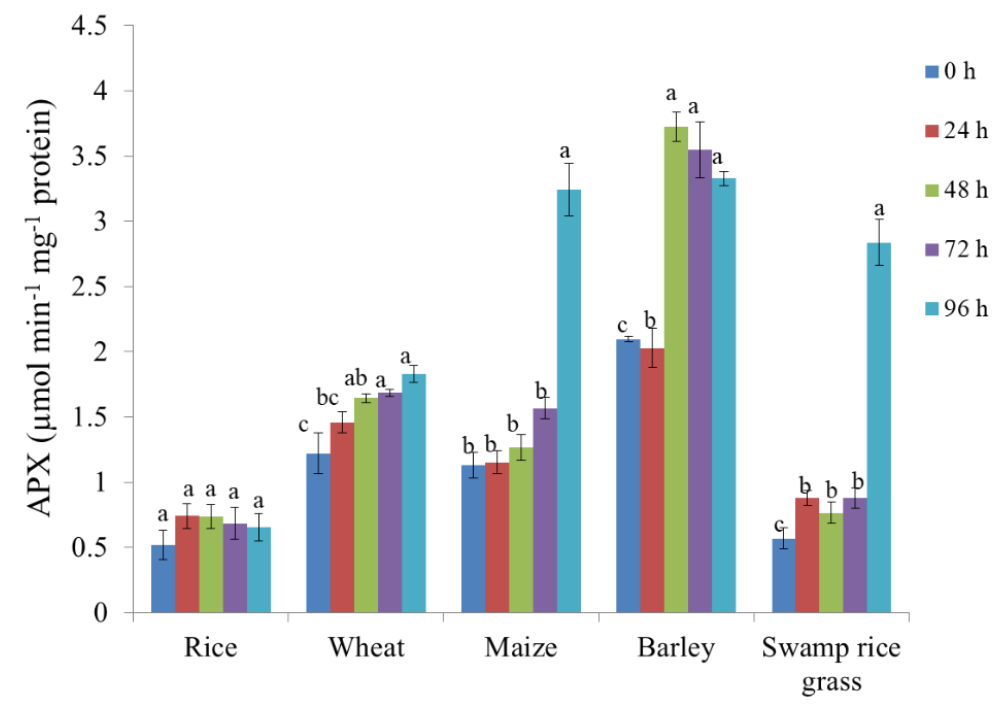

Figure 3. Activities of ascorbate peroxidase (APX) in leaves of rice, wheat, maize, barley and swamp rice grass plants inoculated with MoT isolate. Bars represent the mean values \pm standard error 
obtained for three independent experiments. Mean values in each treatment with the same letter(s) are not significantly different as assessed by Fisher's protected least significant difference (LSD) test at $\mathrm{p} \leq 0.05$.

Increased GPX activity was observed in wheat, maize, barley and swamp rice grass after inoculation with MoT. The increase of GPX activity was higher in swamp rice grass (203\%) followed by barley (202\%), maize (167\%) and wheat (52\%) at 96 hai compared to control plant. Unlike the other plants included in this study, rice showed decreased GPX activity after inoculation with MoT (Figure 4).

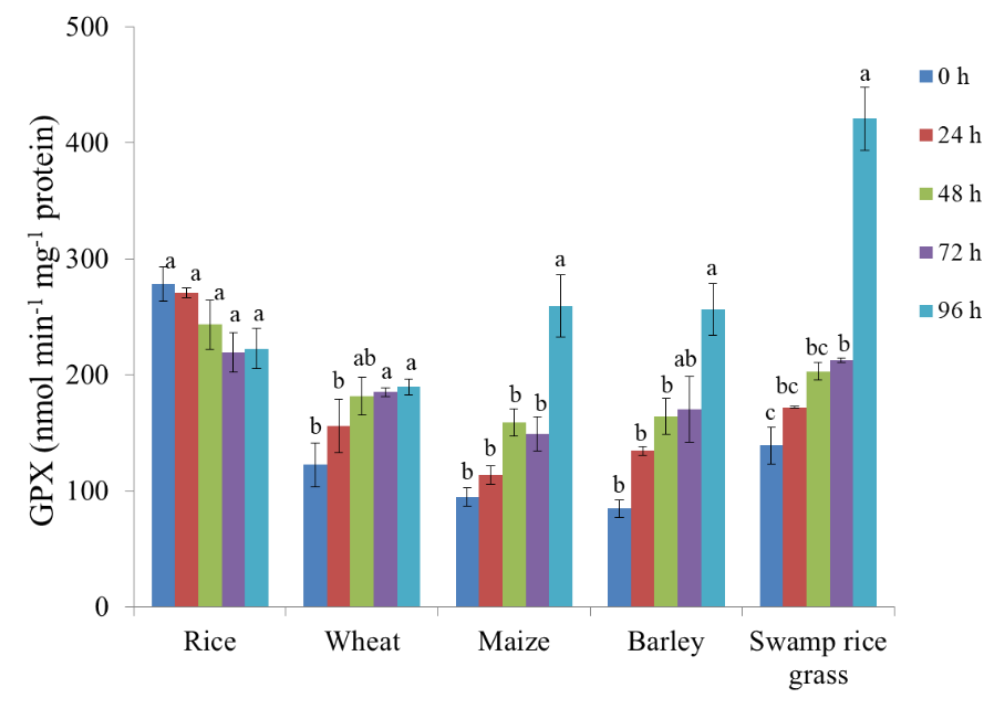

Figure 4. Activities of glutathione peroxidase (GPX) in leaves of rice, wheat, maize, barley and swamp rice grass plants inoculated with MoT isolate. Bars represent the mean values \pm standard error obtained for three independent experiments. Mean values in each treatment with the same letter(s) are not significantly different as assessed by Fisher's protected least significant difference (LSD) test at $\mathrm{p} \leq 0.05$.

The activity of GST increased in all plants due to the inoculation by MoT. Swamp rice grass inoculated with MoT showed a significant increase in the GST activity (227\%) at 96 hai compared to the control plants. Increased GST activity was also recorded in, wheat, maize and barley plant which was 74\%,66\%, 167\%, respectively, at 96 hai compared to their respective controls. However, only a little increased GST activity was observed in rice at 96 hai, which was $21 \%$ higher than the control (Figure 5).

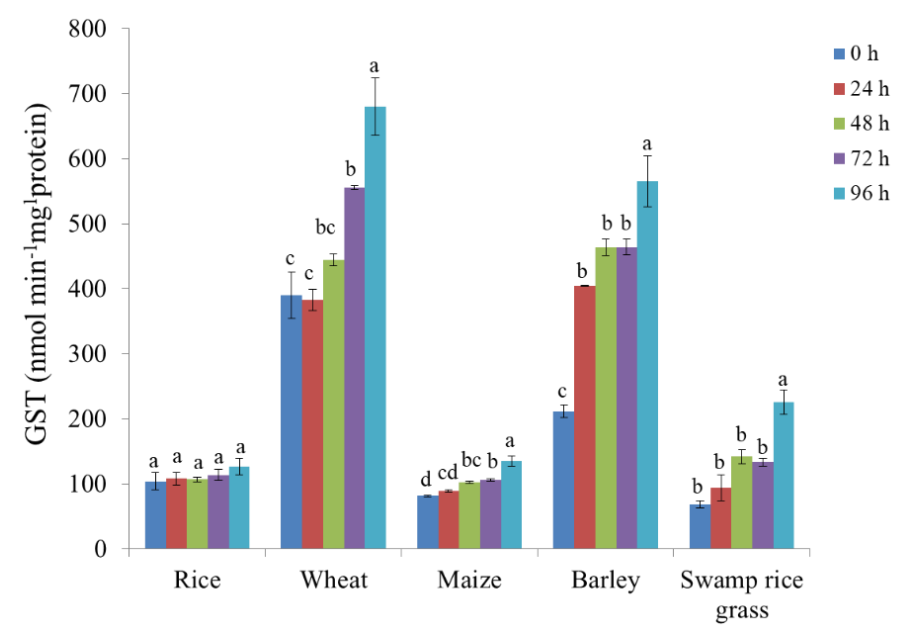

Figure 5. Activities of glutathione $S$-transferase (GST) in leaves of rice, wheat, maize, barley and swamp rice grass plants inoculated with MoT isolate. Bars represent the mean values \pm standard error obtained for three independent experiments. Mean values in each treatment with the same 
letter(s) are not significantly different as assessed by Fisher's protected least significant difference (LSD) test at $\mathrm{p} \leq 0.05$.

Enhanced POX activity was observed in all plants treated with MoT compared to the control. The highest POX activity was observed at 96 hai in all plants except rice. Wheat, maize, barley and swamp rice grass showed 517, 538, 885 and 404\% higher POX activity over control. In rice, increased POX activity (118\%) was observed at 48 hai but decreased with the progression of time after inoculation (Figure 6).

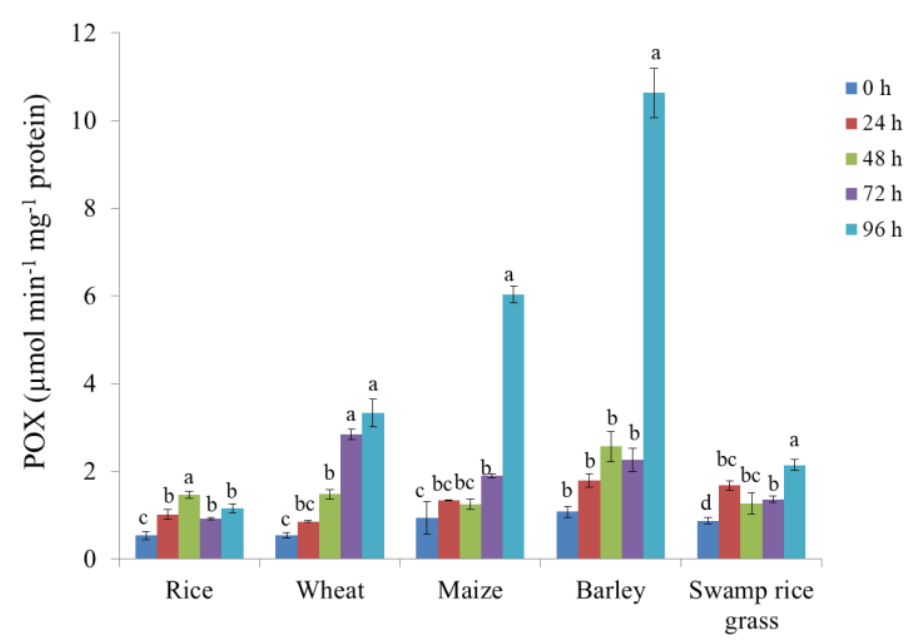

Figure 6. Activities of peroxidase (POX) in leaves of rice, wheat, maize, barley and swamp rice grass plants inoculated with MoT isolate. Bars represent the mean values \pm standard error obtained for three independent experiments. Mean values in each treatment with the same letter(s) are not significantly different as assessed by Fisher's protected least significant difference (LSD) test at $\mathrm{p} \leq 0.05$.

\subsection{Concentration of $\mathrm{H}_{2} \mathrm{O}_{2}$}

The concentration of $\mathrm{H}_{2} \mathrm{O}_{2}$ in different plants varied at different sampling times after MoT inoculation. A significant increase of $\mathrm{H}_{2} \mathrm{O}_{2}$ concentration was observed in rice plant after inoculation of MoT and the maximum concentration $(87 \%)$ was recorded at 48 hai over control and then decreased. However, $\mathrm{H}_{2} \mathrm{O}_{2}$ concentrations in wheat, maize and barley also increased at 24 hai and decreased at 48 hai and then again increased with the progression time after inoculation. In case of swamp rice grass, a lower concentration of $\mathrm{H}_{2} \mathrm{O}_{2}$ was observed at $24 \mathrm{~h}$ after inoculation and then increased with the progression of infection time (Figure 7).

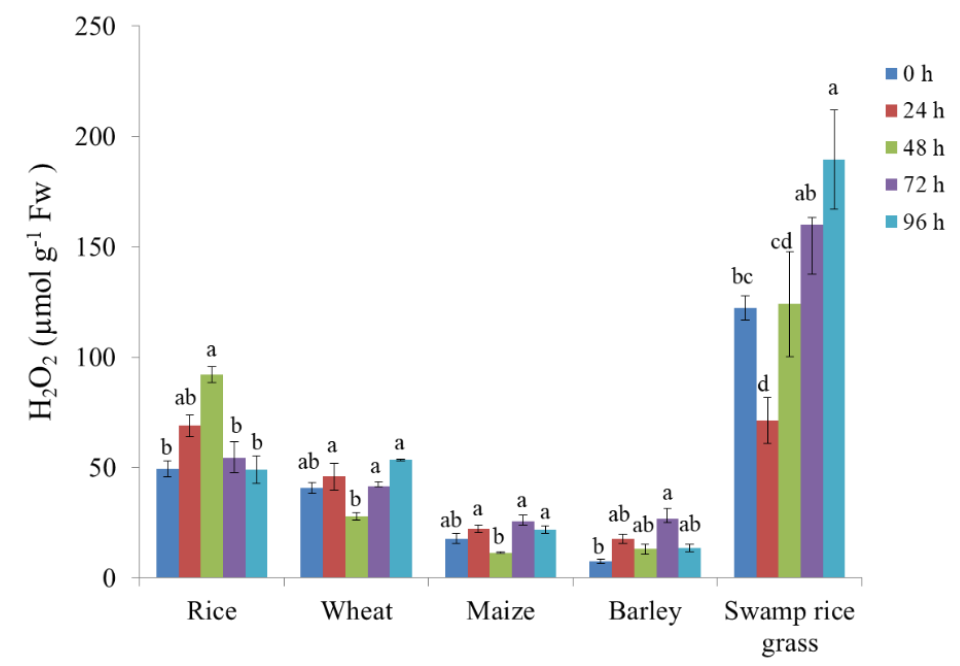

Figure 7. The concentration of hydrogen peroxide $\left(\mathrm{H}_{2} \mathrm{O}_{2}\right)$ in leaves of rice, wheat, maize, barley and swamp rice grass plants inoculated with MoT isolate. Bars represent the mean values \pm standard 
error obtained for three independent experiments. Mean values in each treatment with the same letter(s) are not significantly different as assessed by Fisher's protected least significant difference (LSD) test at $\mathrm{p} \leq 0.05$.

\subsection{Correlations and Principal Component Analysis}

The correlation study revealed that the enzymes CAT, APX, GPX, GST and POX had moderate to high correlation (Fig. 8A). Importantly, GPX had the strongest influence on detoxifying $\mathrm{H}_{2} \mathrm{O}_{2}$. However, the principal component analysis showed the similarities among the different studied attributes (Figure 8B). The activities of the antioxidant enzymes are highly affected by hosts; the exceptions were CAT, which was not substantially affected.
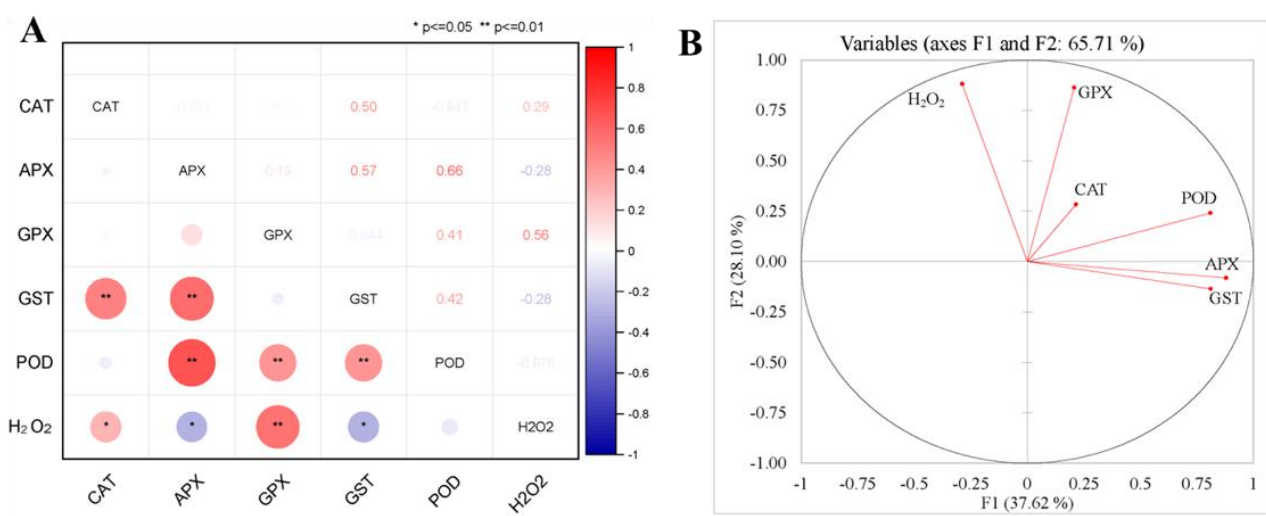

Figure 8. Correlation matrix (Pearson) and Principal component analysis (PCA) of different studied attributes.

\section{Discussion}

Wheat blast has emerged as a serious threat to wheat production in South Asia as the pathogen can move by seed or by air or reside in another host for overwintering [7]. In this study, we assessed the susceptibility of some cereals and weeds to MoT fungus and with concurrent determination of sporulation potentials. Seedlings of wheat, barley, maize and swamp grass were susceptible to MoT and produced variable number of conidia, therefore, considered as a host for MoT. However, we did not find any interaction (hypersensitivity induced cell death) of this pathogen with rice plant in our laboratory conditions hence considered as non-host of MoT. Under both biotic and abiotic stresses, plants react by overgeneration of ROS, especially $\mathrm{H}_{2} \mathrm{O}_{2}$, which is not only a sign of oxidative damage but also initiates a signaling cascade. However, the role of ROS will be a boon or bane depends on the performance of the antioxidant defense system [35, 36, 37]. In this study, we also determined some of the $\mathrm{H}_{2} \mathrm{O}_{2}$-detoxifying enzymes' activities in plants inoculated by MoT. Our result showed that APX, GPX, GST and POX activities significantly increased after inoculation of plants by MoT in the late stage of infection in the host plant whereas APX, GPX and POX activities were increased at an early stage of infection in nonhost plants but at a slow rate. Only GPX activity was decreased in rice plant after inoculation by MoT. Early induction of $\mathrm{H}_{2} \mathrm{O}_{2}$ concentration was observed in rice plant, whereas the late accumulation occurred in other plants, which indicates that early accumulation of $\mathrm{H}_{2} \mathrm{O}_{2}$ in the plant might be important for resistant response to MoT.

MoT are generally dispersed from one place to another by air or seeds and overwinters in a diverse host for their survival. We showed that MoT isolates infecting wheat could also infect barley and swamp grass and produced typical blast symptoms hence considered as highly susceptible (host). In maize, MoT produced diamond-shaped symptoms but no defined elliptical or eye-shaped lesion was developed and considered as moderately resistant. However, MoT isolate did not produce any symptom on rice plant, thus considered as resistant to MoT isolate. Our result is consistent with the result reported by Araujo et al. [38] that the rice plant did not produce any necrosis or hypersensitive response cell death when inoculated with wheat-infecting $M$. oryzae isolates (non-host). In 
Bangladesh, maize is the third important cereals crops after rice and wheat [39] and barley is a non-major cereal but widely grown in north Bengal of Bangladesh [40]. Wheat, barley and maize are grown during winter in Bangladesh. Therefore, there is a high chance of host jump of MoT from a contaminated wheat field to maize and barley field. It has been shown that the wheat blast isolates collected from a wheat neck of Kentucky, USA in 2011, was evolved from annual ryegrass through host jump [41]. Jia et al. [42] reported that $M$. oryzae isolates of rice could produce earlier symptoms on Carolina foxtail millet than some susceptible cultivar of rice, suggesting a potential alternative host of rice blast pathogen. Although MoT infects leaf but infection at heading stage is more destructive [7]. Whether this pathogen can also infect at the heading stage of barley and maize also need to be tested. As the pathogen can infect several grass species, weeds host in the field play a key role as a source of primary and secondary inoculum by functioning as bridges between wheat fields and cropping seasons [43]. We tested several weeds grown in wheat fields. Among the grasses, only swamp rice grass was susceptible to MoT isolate. Swamp rice grass is a common weed of Bangladesh that grows in both rice and wheat field. Our results suggest that MoT could potentially use barley, maize and swamp grass as a host or alternative host for their survival.

It is proposed that the number of conidia produced by the pathogen may play a role in disease outbreaks [28]. Although MoT can infect wheat, maize, barley and swamp grass there were significant differences in the conidia production among the hosts. Wheat produced ten times more conidia/g leaf than barley and swamp rice grass and a hundred times more conidia/g leaf than maize. Wheat is the major host of MoT, therefore, it is likely to produce more conidia than other crops tested. However, both barley (310000-370000) and swamp rice grass (280000-310000) produced ten times lower conidia than wheat $(13,00,000-15,00,000)$, but this number is significant enough for disease development. Laboratory experiments showed that a concentration of 24000 conidia/spike can cause high levels of blast severity on highly susceptible cultivars [44]. Maize seedlings showed moderate resistance to MoT that produced a significantly lower number of conidia (1000-1400) than barley and swamp grass. Cruz et al. [28] reported that a susceptible wheat cultivar produced a greater number of conidia than a resistant one.

Production of ROS, especially $\mathrm{H}_{2} \mathrm{O}_{2}$, is an important plant defense response against pathogen infection [45]. However, the concentration of $\mathrm{H}_{2} \mathrm{O}_{2}$ in the plant cell is crucial for proper biological activities; otherwise, it damages cell. To protect the plant from this, damaging plant employed enzymatic and non-enzymatic mechanisms to remove excess $\mathrm{H}_{2} \mathrm{O}_{2}$ from the cell. $[46,47,48]$. Among the enzymes, CAT has the highest turnover rate and plays a key role in removing $\mathrm{H}_{2} \mathrm{O}_{2}$ from cells. In our study, we observed enhanced catalase activity after inoculation of all plants by MoT. However, in different hosts, the enhancement of CAT activity was observed at various time points after inoculation of MoT. In wheat, barley and swamp rice grass, CAT activity increased transiently at an early stage (24 hai) of infection and then decreased at the disease development stage (96 hai). A similar pattern of CAT activity was observed in other pathosystems, including B. cinerea-Tomato, M. oryzae-Wheat $[25,49]$. It has been reported that in an incompatible reaction, CAT activities were increased during the initial stage of infection and decreased after the formation of necrotic lesion. Moreover, host CAT enzymes activity depends on the interacting partners and spatial and temporal parameters during disease development $[49,50]$. However, down-regulation of CAT activity in the susceptible host could be a consequence of enhanced proteolysis that is induced by oxidative stress [51]. Although a continuous increase of CAT activity was observed in rice plant until 96 hai but it was nonsignificant suggesting that enhanced CAT activity more related with susceptibility of the plant rather than resistance.

A consistent increase of APX, GST and POD activities were observed during the infection process of MoT. In wheat, barley maize and swamp rice grass APX showed an enhanced activity from 24-96 hai, whereas, in rice, the APX activity increased from 24-48 hai and then decreased slowly (Figure 3). This result is very much similar to rice-M. grisea pathosystem where mRNA expression of two isoforms of APX genes were up-regulated 
in both compatible and incompatible interactions but earlier in incompatible interactions. The early accumulation of APX in incompatible interaction is probably involved in HR response in plant [52].

The plant GSTs are multifunctional enzymes encoded by large gene families [53]. The expression of GST gene is highly induced in the early phase of pathogen attack, whereas silencing or overexpression of these genes modified the disease symptoms and pathogen multiplication rate. In our study, we observed increased GST activity at a late stage (96 hai) after MoT inoculation of all plants. However, \% increase of GST activity in susceptible plants was higher than resistant. GST activity has been shown to induce in both the susceptible and resistant plant by the attack of hemibiotrophic pathogens. Some of the genes of this family have shown important for resistance response, while some of them are indispensable for the susceptibility of many plants. Dean et al. [54] reported that silencing of a GST gene, namely, NbGSTU1 induces $67 \%$ more colonization and $130 \%$ more lesion formation in Nicotiana benthamiana plant inoculated with Colletotrichum orbiculare. In contrast, silencing of a GST gene from tobacco increase resistance towards a hemibiotrophic oomycete Phytophthora parasitica suggesting that individual GST genes provide an antioxidative capacity that favored the fungal growth and suppress plant resistance [55].

GPX is non-heme-thiol peroxidase that plays an important role in ROS detoxification by scavenging $\mathrm{H}_{2} \mathrm{O}_{2}$ [56]. Hydrogen peroxide, produced during an incompatible pathogen interaction, was found to induce GPX expression in soybean [57]. In this study, GPX enzyme activity in wheat, barley, maize and swamp rice grass increased as time progressed, while a reduction in the enzyme activity was observed in rice plants. Agrawal et al. [58] reported that $M$. grisea inoculation in rice induced a phospholipid hydroperoxide GPX expression in both compatible and incompatible interactions initially and later, the expression decreased in incompatible interaction. A similar pattern of GPX gene expression was also observed in M. grieasea-Finger millet pathosystem. The relative expression of GPX increased in incompatible interaction with the progress of time, whereas it decreased in resistant genotypes [59].

POX is one of the most important enzymes involved in the production of apoplastic reactive oxygen species, thereby creating a toxic environment for the pathogens to grow and participate in cell wall lignification [60]. Several researchers reported that POX activity enhanced in the plant due to the inoculation of pathogen both in compatible and incompatible interactions. However, the \% increase of POX activity is higher in the resistant plant than susceptible [25]. In our study, we observed a decreased POX activity in rice plants after $48 \mathrm{~h}$ of MoT inoculation, while increased POD activity was observed in other plants at a late stage (96 hai). Jacob et al. [59] reported a similar phenomenon when working with M. oryzae-finger millet pathosystem. POX gene expression was decreased in incompatible interaction and increased incompatible interactions at the disease progression stage. The author concluded that different members of peroxidase gene family might be differentially expressed in different genotypes in response to pathogen attack or other environmental factors.

The $\mathrm{H}_{2} \mathrm{O}_{2}$ has been reported to inhibit biotrophic pathogens but provided benefit to necrotrophs. However, in hemibiotrophic, $\mathrm{H}_{2} \mathrm{O}_{2}$ inhibit pathogen during the biotrophs phase but accumulated in the host massively during the reproduction stage of the pathogen [24]. In wheat, barley, maize and swamp rice grass, $\mathrm{H}_{2} \mathrm{O}_{2}$ concentration was slightly increased after pathogen inoculation then decreased and largely accumulated at the disease development stage (96 hai) (Figure 7). On the other hand, in rice, $\mathrm{H}_{2} \mathrm{O}_{2}$ concentration was higher at an early stage of infection (48 hai) but decreased at the disease development stage. Poudel et al. [61] reported that early accumulation of $\mathrm{H}_{2} \mathrm{O}_{2}$ is directly correlated with lignification of the host plant to protect the plant from the pathogen penetration. However, the large accumulation of $\mathrm{H}_{2} \mathrm{O}_{2}$ at a later stage is attributed to peroxisomal damage during the general tissue collapse [24]. Importantly, these enzymes showed a diverse association with the level of $\mathrm{H}_{2} \mathrm{O}_{2}$ in regards to the treatment duration and plant species (Figure 8).

\section{Conclusions}


The antioxidant enzymes activities such as APX, GST, GPX and POX was higher at the later stages of infection in host plants while the activities were enhanced in the early stage of infection in a non-host plant (rice) but very slowly. In hemibiotrophic interactions, some defense genes were found to be up-regulated earlier incompatible interactions but more strongly at a later stage in incompatible interactions [62]. The mechanisms of rice non-host resistance against MoT is very similar to non-host resistance of Arabidopsis against Pseudomonas syringae pv phaseolicola where defense genes are up regulated earlier in Arabidopsis is similar to resistant plant but at a slower rate [63]. The very early inducible defense does not proceed to a step that induced hypersensitive cell death in rice. Interestingly, we observed an early CAT activity in all susceptible plants (compatible interaction) with concurrent reduction of $\mathrm{H}_{2} \mathrm{O}_{2}$ concentration implying the removal of $\mathrm{H}_{2} \mathrm{O}_{2}$ by catalase. A very little induction of CAT activity was observed in the resistant plant, whereas higher accumulation of $\mathrm{H}_{2} \mathrm{O}_{2}$ was observed at an early stage of MoT inoculation. It has been suggested that $\mathrm{H}_{2} \mathrm{O}_{2}$ accumulation makes the plant resistant, while both early and late accumulation CAT makes the plant more susceptible. Probably $\mathrm{H}_{2} \mathrm{O}_{2}$ participates in active defense by arresting the growth of pathogen by massive accumulation during an early stage of infection in incompatible interaction [64]. Whereas, very little accumulation of $\mathrm{H}_{2} \mathrm{O}_{2}$ induces conidial penetration and hyphal growth in host tissues during the initial biotrophic phase of the interaction incompatible interactions. However, a detailed study of individual host-pathogen interactions is required to understand the role of specific antioxidant enzyme in a host and non-host interactions involving a deadly pathogen [65]. It is also possible that apart from the antioxidant enzymes the nonenzymatic antioxidants might play a vital role in the modulation of $\mathrm{H}_{2} \mathrm{O}_{2}$ content and a better survival of plants under wheat blast pathogen attack. Therefore, further research should focus on the coordinated defense mechanisms in wheat.

Author Contributions: Authors contributions: Conceptualization, T.I.; methodology, D.R.G.; S.K.; M.Z.S., A.S. and M.M.R.; formal analysis, D.R.G.; N.U.M. and M.H.; original draft preparation, D.R.G.; writing-reviewing and editing, T.I.; M.H.; K.A.A. M.R. and D.R.G.; Supervision, T.I. All authors have read and approved the manuscript.

Funding: This research received no external funding.

Conflicts of Interest: The authors declare no conflict of interest.

\section{References}

1. Vales, M.J.; Huallpa, B.; Anzoátegui, T.; Mostacedo, B.; Cazon, M.I. Efficient breeding strategy for wheat blast disease resistance in Bolivia - use of the experience acquired on rice blast. In: EM Del Ponte, GC Bergstrom, W Pavan, A Lazzaretti, JM Cunha Fernandes, eds. Book of Abstracts, 5th International Symposium on Fusarium Head Blight and 2nd International Workshop on Wheat Blast, Florianopolis, SC, Brazil. Passo Fundo, Brazil: Universidad de Passo Fundo. 2016,130.

2. Islam, M.T.; Croll, D.; Gladieux, P.; Soanes, D.M.; Persoons, A.; Bhattacharjee, P.; Hossain, M.S.; Gupta, D.R.; Rahman, M.M.; Mahboob, M.G.; Cook, N.; Salam, M.U.; Surovy, M.Z.; Sancho, V.B.; Maciel, J.L.N.; NhaniJúnior, A.; Castroagudín, V.L.; de Assis Reges J.T.; Ceresini, P.C.; Ravel, S.; Kellner, R.; Fournier, E.; Tharreau, D.; Lebrun, M.H.; McDonald, B.A.; Stitt, T.; Swan, D.; Talbot, N.J.; Saunders, D.G.O.; Win, J.; Kamoun, S. Emergence of wheat blast in Bangladesh was caused by a South American lineage of Magnaporthe oryzae. BMC Biol. 2016,14,84.

3. Kamoun, S.; Talbot, N.J.; Islam, M.T. Plant health emergencies demand open science: Tackling a cereal killer on the run. PLoS Biol. 2019,17,e3000302.

4. Tembo, B.; Mulenga, R.M.; Sichilima, S.; M'siska, K.K.; Mwale, M.; Chikoti, P.C.; Singh, P.K.; Pedley, K.F.; Peterson, G.L.; Singh, R.P.; Braun, H.J. Detection and characterization of fungus (Magnaporthe oryzae pathotype Triticum) causing wheat blast disease on rain-fed grown wheat (Triticum aestivum L.) in Zambia. PLoS ONE. 2020,15, e0238724.

5. Perfect, S.E.; Green, J.R. Infection structures of biotrophic and hemibiotrophic fungal plant pathogens. Mol. Plant Pathol. 2001,2,101-108.

6. Fernandez, J.J.; Orth, K. Rise of a cereal killer: The biology of Magnaporthe oryzae biotrophic growth. Trends Microbiol. 2018, 26:582-597.

7. Islam, M.T.; Kim, K.H.; Choi, J. Wheat Blast in Bangladesh: The Current Situation and Future Impacts. Plant Pathol J. 2019,35,110 . 
8. Urashima, A.S.; Lavorent, N.A.; Goulart, C.P.; Mehta, Y.R. Resistance spectra of wheat cultivars and virulence diversity of Magnaporthe grisea isolates in Brazil. Fitopatología Brasilera. 2004,29,511-518.

9. Maciel, J.L.N.; Ceresini, P.C.; Castroagudin, V.L.; Zala, M.; Kema, G.H.; McDonald, B.A. Population structure and pathotype diversity of the wheat blast pathogen Magnaporthe oryzae 25 years after its emergence in Brazil. Phytopathol. 2014,104,95-107.

10. Durante, L.G.Y.; Maria, L.; Bacchi, A.; de Souza, J.E.; Graichen, F.A.S. Reaction of wheat plants and alternative hosts to Magnaporthe oryzae. Arq. Inst. Biol. 2018,85,1_6.

11. Inoue, Y.; Vy, T.T.P.; Yoshida, K.; Asano, H.; Mitsuoka, C.; Asuke, S.; Anh, V.L.; Cumagun C.J.R.; Chuma, I.; Terauchi, R.; Kato, K.; Mitchell, T.; Valent, B.; Farman, M.; Tosa, Y. Evolution of the wheat blast fungus through functional losses in a host specificity determinant. Sci. 2017,357,80-83.

12. Urashima, A.S.; Igarashi, S.; Kato, H. Host range, mating type and fertility of Pyricularia grisea from wheat in Brazil. Plant Dis.1993,77,1211-1216.

13. Aghnoum, R.; Bvindi, C.; Menet, G.; D’hoop, B.; Maciel, J.L.N.; Niks, R.E. Host/nonhost status and genetics of resistance in barley against three pathotypes of Magnaporthe blast fungi. Euphytica. 2019,215,116.

14. Zhan, S.W.; Mayama, S.; Tosa, Y. Identification of two genes for resistance to Triticum isolates of Magnaporthe oryzae in wheat. Genome. 2008, 51,216-221.

15. Lee, H.A.; Lee, H.Y.; Seo, E.; Lee, J.; Kim, S.B.; Oh, S.; Choi, E.; Lee, S.E.; Choi, D. Current understandings of plant nonhost resistance. Mol. Plant Microbe Interact. 2017,30,5-15.

16. Yao, N.; Imai, S.; Tada, Y.; Nakayashiki, H.; Tosa, Y.; Park, P.; Mayama, S. Apoptotic cell death is a common response to pathogen attack in oats. Mol. Plant Microbe Interact. 2002;15,1000- 1007.

17. Lamb, C.; Dixon, R.A. The oxidative burst in plant disease resistance. Ann. Rev. Plant Physiol Plant Mol Biol. 1997,48,251-275.

18. Magbanua, Z.V.; De Moraes, C.M.; Brooks, T.D.; Williams, W.P.; Luthe, D.S. Is catalase activity one of the factors associated with maize resistance to Aspergillus flavus? Mol. Plant-Microbe Interact. 2007,20,697-706.

19. Mittler, R.; Vanderauwera, S.; Suzuki, N.; Miller, G.; Tognetti, V.B.; Vandepoele, K.; Gollery, M.; Shulaev, V.; Van Breusegem, F. ROS signalling: the new wave? Trends Plant Sci. 2011,16,300-309.

20. Del Río, L.A. ROS and RNS in plant physiology: an overview. J. Exp. Bot. 2015,66,2827-2837.

21. Foyer, C.H.; Noctor, G. Redox regulation in photosynthetic organisms: signaling, acclimation, and practical implications. Antioxid. Redox Signal. 2009,11,861-905.

22. O’Brien, J.A.; Daudi, A.; Finch, P.; Butt, V.S.; Whitelegge, J.P.; Souda, P.; Ausubel, F.M.; Bolwell, G.P. A peroxidase-dependent apoplastic oxidative burst in cultured arabidopsis cells functions in MAMP-elicited defense. Plant Physiol. 2012,158,2013-2027.

23. Able, A.J. Role of reactive oxygen species in the response of barley to necrotrophic pathogens. Protoplasma. 2003,221,137-143.

24. Shetty, N.P.; Mehrabi, R.; Lütken, H.; Haldrup, A.; Kema, G.H.J.; Collinge, D.B.; Jørgensen, H.J.L. Role of hydrogen peroxide during the interaction between the hemibiotrophic fungal pathogen Septoria tritici and wheat. New Phytol. 2007,174,637-647.

25. Debona, D.; Rodrigues, F.A.; Rios, J.A.; Nascimento, K.J.T. Biochemical changes in the leaves of wheat plants infected by Pyricularia oryzae. Biochem. Cell Biol. 2012,102,1121-129.

26. Gupta, D.R.; Surovy, M.Z.; Mahmud, N.U.; Chakrabarty, M.; Paul, S.K.; Hossain, M.S.; Bhattacharjee, P.; Mehbub, M.S.; Rani, K.; Yeasmin, R.; Rahman, M.; Islam, M.T. Suitable methods for isolation, culture, storage and identification of wheat blast fungus Magnaporthe oryzae Triticum pathotype. Phytopathol Res. 2020,2, 30.

27. Urashima, A.S.; Stabili, A.; Galbieri, R. DNA fingerprinting and sexual characterization revealed two distinct populations of Magnaporthe grisea in wheat blast from Brazil. Czech J. Genet Plant Breed. 2005,41,238-245.

28. Cruz, C.D.; Kiyuna, J.; Bockus, W.W.; Todd, T.C.; Stack, J.P.; Valent, B. Magnaporthe oryzae conidia on basal wheat leaves a potential source of wheat blast inoculum. Plant Pathol. 2015,64,1491-1498.

29. Bradford, M.M. A rapid and sensitive method for the quantitation of microgram quantities of protein utilizing the principle of protein-dye binding. Anal Biochem. 1976,72,248-254.

30. Yu, C.W.; Murphy, T.M.; Lin, C.H. Hydrogen peroxide-induces chilling tolerance in mung beans mediated through ABA-independent glutathione accumulation. Funct. Plant Biol. 2003,30,955-963

31. Hossain, M.A.; Hasanuzzaman, M.; Fujita, M. Up-regulation of antioxidant and glyoxalase systemsby exogenous glycinebetaine and proline in mung bean confer tolerance to cadmium stress. Physiol. Mol. Biol. Plants. 2010,16,259-272.

32. Nakano, Y.; Asada, K. Hydrogen peroxide is scavenged by ascorbate-specific peroxidase in spinach chloroplasts. Plant Cell Physiol. 1981,22,867-880.

33. Hasanuzzaman, M.; Hossain, M.A.; Fujita, M. Selenium-induced up-regulation of the antioxidant defense and methylglyoxal detoxification system reduces salinity-induced damage in rapeseed seedlings. Biol. Trace Elem. Res. 2011,143,1704-21.

34. Hemeda, H.M.; Klein, B.P. Effects of naturally occurring antioxidants on peroxidase activity of vegetable extracts. J. Food Sci. 1990,55,184-185.

35. García-Caparrós, P.; De Filippis, L.; Gul, A.; Hasanuzzaman, M.; Ozturk, M.; Altay, V.; Lao, M.T. Oxidative stress and antioxidant metabolism under adverse environmental conditions: A review. Bot. Rev. 2020,10.1007/s12229-020-09231-1. 
36. Hasanuzzaman, M.; Bhuyan, M.H.M.B.; Parvin, K.; Bhuiyan, T.F.; Anee, T.I.; Nahar, K.; Hossen, M.S.; Zulfiqar, F.; Alam, M.M.; Fujita, M. Regulation of ROS metabolism in plants under environmental stress: A review of recent experimental evidence. Int. J. Mol. Sci. 2020,21,8695.

37. Hasanuzzaman, M.; Bhuyan, M.H.M.B.; Zulfiqar, F.; Raza, A.; Mohsin, S.M.; Mahmud, J.A.; Fujita, M.; Fotopoulos, V. Reactive oxygen species and antioxidant defense in plants under abiotic stress: Revisiting the crucial role of a universal defense regulator. Antioxidants. 2020,9,681.

38. Araujo, L.; Soares, J.M.; de Filippi, M.C.C.; Rodrigues, F.A. Cytological aspects of incompatible and compatible interactions between rice, wheat and the blast pathogen Pyricularia oryzae. Sci. Agric. 2016,73,177-183.

39. Monlruzzaman, M.; Karim, M.K.; Alam, Q.M. Agro-economic analysis of maize production in Bangladesh: a farm level study. Bangladesh J. Agril. Res. 2009,34,15-24.

40. Khatun, M.; Khandoker, S.; Rashid, M.A.; Kundu, N.D.; Matin, M.A. Profitability of barley cultivation in selected areas of Bangladesh. BOU J. Agric. Rural Dev. 2018,10,57-67.

41. Farman, M.; Peterson, G.; Chen, L.; Starnes, J.; Valent, B.; Bachi, P.; Murdock, L.; Hershman, D.; Pedley, K.; Fernandes, J.M,; Bavaresco, J. The Lolium pathotype of Magnaporthe oryzae recovered from a single blasted wheat plant in the United States. Plant Dis. 2017,101,684-692.

42. Jia, Y.; Gealy, D.; Lin, M.J.; Wu, L. Carolina Foxtail (Alopecurus carolinianus): Susceptibility and suitability as an alternative host to rice blast disease (Magnaporthe oryzae [formerly M. grisea]) Plant Dis. 2008,92,504-508.

43. Ceresini, P.C.; Castroagudín, P.L.; Rodrigues, F.A.; Rios, J.A.; Aucique- Pérez, C.E.; Moreira, S.I.; Croll, D.; Alves, E.; de Carvalho, G.; Maciel, J.L.N.; McDonald B.A. Wheat blast: from its origins in South America to its emergence as a global threat. Mol. Plant Pathol. 2019,20,155-172.

44. Cruz, C.D.; Bockus, W.W.; Stack, J.P.; Tang, X.; Valent, B.; Pedley, K.F.; Peterson G.L. Preliminary assessment of resistance among U.S. wheat cultivars to the Triticum pathotype of Magnaporthe oryzae. Plant Dis. 2012,96,1501-5.

45. Torres, M.A. ROS in biotic interactions. Physiol. Plant. 2010,138,414-429.

46. Apel, K.; Hirt, H. Reactive oxygen species: metabolism, oxidative stress, and signal transduction. Annu. Rev. Plant Biol. 2004,55,373-399.

47. Gechev, T.S.; Van Breusegem, F.; Stone, J.M.; Denev, I.; Laloi, C. Reactive oxygen species as signals that modulate plant stress responses and programmed cell death. Bioessays. 2006,28,1091-1101.

48. Miller, G.; Suzuki, N.; Ciftci-Yilmaz, S.; Mittler, R. Reactive oxygen species homeostasis and signalling during drought and salinity stresses. Plant Cell Environ. 2010,33,453-467.

49. KuZniak, E.; Sk ᄀodowska, M. Fungal pathogen-induced changes in the antioxidant systems of leaf peroxisomes from infected tomato plants. Planta. 2005,222,192-200.

50. Havelda, Z.; Maule, A.J. Complex spatial responses to cucumber mosaic virus infection in susceptible Cucurbita pepo cotyledons. Plant Cell. 2000,12,1975-1985.

51. Quan, L.J.; Zhang, B.; Shi, W.W.; Li, H.Y. Hydrogen peroxide in plants: a versatile molecule of the reactive oxygen species network. J. Integr. Plant Biol. 2008,50,2-18.

52. Agrawal, G.K.; Jwa, N.S.; Iwahashi, H.; Rakwal, R. Importance of ascorbate peroxidase OsAPX1 and OsAPX2 in the rice pathogen response pathways and growth and reproduction revealed by their transcriptional profiling. Gene. 2003,322,93-103.

53. Gullner, G.; Komives, T.; Király, L.; Schröder, P. Glutathione S-Transferase Enzymes in Plant-Pathogen Interactions. Front. Plant Sci. 2018,9,1836.

54. Dean, J.D.; Goodwin, P.H.; Hsiang, T. Induction of glutathione S-transferase genes of Nicotiana benthamiana following infection by Colletotrichum destructivum and C. orbiculare and involvement of one in resistance. J. Exp. Bot. 2005,56,1525-1533.

55. Hernández, I.; Chacón, O.; Rodriguez, R.; Portieles, R.; López, Y.; Pujol, M.; Borrás-Hidalgo, O. Black shank resistant tobacco by silencing of glutathione S-transferase. Biochem. Biophys Res Commun. 2009,387,300-304.

56. Bela, K.; Horváth, E.; Gallé, Á.; Szabados, L.; Tari, I.; Csiszár, J. Plant glutathione peroxidases: emerging role of the antioxidant enzymes in plant development and stress responses. J. Plant Physiol. 2015,176,192- 201.

57. Levine, A.; Tenhaken, R.; Dixon, R.; Lamb, C. $\mathrm{H}_{2} \mathrm{O}_{2}$ from the oxidative burst orchestrates the plant hypersensitive disease resistance response. Cell. 1994,79,583-593.

58. Agrawal, G.K.; Rakwal, R.; Jwa, N.S.; Agrawal, V.P. Effects of signaling molecules, protein phosphatase inhibitors and blast pathogen (Magnaporthe grisea) on the mRNA level of a rice (Oryza sativa L.) phospholipid hydroperoxide glutathione peroxidase (OsPHGPX) gene in seedling leaves. Gene. 2002,283,227-236.

59. Jacob, J.; Pusuluri, M.; Domathoti, B.; Das, I.K. Magnaporthe grisea infection modifies expression of anti-oxidant genes in finger millet [Eleusine coracana (L.) Gaertn.]. J Plant Pathol. 2018. doi.org/10.1007/s42161-018-0162-3.

60. Kärkönen, A.; Kuchitsu, K. Reactive oxygen species in cell wall metabolism and development in plants. Phytochem. 2015,112,2232. 
61. Poudel, A.; Navathe, S.; Chand, R.; Mishra, V.; Singh, P.; Joshi, A. Hydrogen peroxide prompted lignification affects pathogenicity of hemi-biotrophic pathogen Bipolaris sorokiniana to wheat (Triticum aestivum L.). Plant Pathol. J. 2019,35,287-300.

62. Tufan, H.A.; McGrann, G.R.D.; Magusin, A.; Morel, J.B.; Miché, L.; Boyd, L.A. Wheat blast: histopathology and transcriptome reprogramming in response to adapted and nonadapted Magnaporthe isolates. New Phytol. 2009,184,473-484.

63. Tao, Y.; Xie, Z.; Chen, W.; Glazebrook, J.; Chang, H.S.; Han, B.; Zhu, T.; Zou, G.; Katagiri, F. Quantitative nature of Arabidopsis responses during compatible and incompatible interactions with the bacterial pathogen Pseudomonas syringae. Plant Cell. 2003,15,317-330.

64. Shetty, N.P.; Kristensen, B.K.; Newman, M-A.; Møller, K.; Gregersen, P.L.; Jørgensen, H.J.L. Association of hydrogen peroxide with restriction of Septoria tritici in resistant wheat. Physiol. Mol. Plant Pathol. 2003,62,333-346.

65. Islam, M.T.; Gupta, D.R.; Hossain, A.; Roy, K.K.; He, X.; Kabir, M.R.; Singh, P.K.; Khan, MAR; Rahman, M.; Wang, G.L. Wheat blast: a new threat to food security. Phytopathol. Res. 2020,2, 28. 